\title{
Science Academies Refresher Course in Experimental Physics
}

\author{
10-25 August 2017 \\ Department of Physics, Christ Church College, Kanpur (UP) \\ Sponsored by Indian Academy of Sciences, Bengaluru \\ Indian National Science Academy, New Delhi \\ The National Academy of Sciences, India, Allahabad
}

\begin{abstract}
A Refresher Course in Experimental Physics will be held in Christ Church College, Kanpur, from 10th to 25th August 2017 for the benefit of faculty involved in teaching undergraduate and postgraduate courses. Participants in this course will gain hands on experience with about twenty five experiments, with a low cost kit developed for the Indian Academy of Sciences, and manufactured by Ajay Sensors and Instruments in Bangalore. These experiments are in (a) mechanics, (b) heat, (c) electricity both DC and AC, (d) magnetism, (e) relaxation, (f) phase sensitive detection technique, and (g) non-linear dynamics. This course is sponsored by Indian Academy of Sciences, Bangalore; Indian National Science Academy, New Delhi; National Academy of Sciences, India, Allahabad and Christ Church College, Kanpur.
\end{abstract}

Refresher courses in Experimental Physics held so far have been highly successful and the experiments have been included in 125 institutions including universities, autonomous colleges, and advanced scientific institutions involved in education. The course will be directed by Dr. C S Sundar F.A.Sc. UGC has approved two-week Refresher Courses of good standing for promotion, vide notification. F3-1/2009 dated 30 June 2010.

Applications are invited from teachers with experience in teaching undergraduate and postgraduate courses in Physics. Motivated students of BSc and MSc Physics courses with keen interest in Experimental Physics may also apply. The maximum number of seats will be 34 .

Selected participants will be paid actual fare by bus/train to and fro from their place of work not exceeding three tier AC railway fares. Out station participants will be provided boarding and lodging during the Course. Applications should be submitted ONLINE by clicking the following link.

http://web-japps.ias.ac.in: 8080/Refreshcourse/RCMCMC.jsp

A copy of the application form signed by the applicant should also be sent by post to the Course Coordinator. In case of teachers, the form must also be signed and stamped by the Head of the applicants Institution stating that leave will be sanctioned if the applicant is selected for the Course. A recommendation letter from a teacher is essential for student applicants. Scanned copies of the duly signed documents sent by Email will also be accepted. Applications may be sent to:

Course Co-ordinator: Dr. R K Dwivedi, Associate Professor \& Head, Department of Physics, Christ Church P G College, Kanpur 208001 (UP). Contact Phone: 09936966543; Email: rkdwivedi@ hotmail.com

Selected participants will be intimated by 08 July 2017 .

Last Date for Receipt of Applications: 01 July 2017. 